\title{
Strength and Stiffness Analyses of Standard and Double Mortise and Tenon Joints
}

\author{
Seid Hajdarevic, ${ }^{\mathrm{a}, *}$ Murco Obucina, ${ }^{\mathrm{a}}$ Elmedin Mesic, ${ }^{\mathrm{b}}$ and Sandra Martinovic ${ }^{\mathrm{a}}$ \\ This paper investigated the effect of the tenon length on the strength and \\ stiffness of the standard mortise and tenon joints, as well of the double \\ mortise and tenon joints, that were bonded by poly(vinyl acetate) (PVAc) \\ and polyurethane (PU) glues. The strength was analyzed by measuring \\ applied load and by calculating ultimate bending moment and bending \\ moment at the proportional limit. Stiffness was evaluated by measuring \\ displacement and by calculating the ratio of applied force and \\ displacement along the force line. The results were compared with the \\ data obtained by the simplified static expressions and numerical \\ calculation of the orthotropic linear-elastic model. The results indicated \\ that increasing tenon length increased the maximal moment and \\ proportional moment of the both investigated joints types. The analytically \\ calculated moments were increased more than the experimental values \\ for both joint types, and they had generally lower values than the \\ proportional moments for the standard tenon joints, as opposed to the \\ double tenon joints. The Von Mises stress distribution showed \\ characteristic zones of the maximum and increased stress values. These \\ likewise were monitored in analytical calculations. The procedures could \\ be successfully used to achieve approximate data of properties of loaded \\ joints.
}

Keywords: Mortise and tenon joint; Strength; Stiffness; Tenon length; Glue; Finite element method

Contact information: a: Department of Wood Technology, Faculty of Mechanical Engineering, University of Sarajevo, 71000, Sarajevo, Bosnia and Herzegovina; $b$ : Department of Mechanical Design, Faculty of Mechanical Engineering, University of Sarajevo, 71000, Sarajevo, Bosnia and Herzegovina;

* Corresponding author: hajdarevic@mef.unsa.ba

\section{INTRODUCTION}

Mortise and tenon joints have a wide range of use in furniture frame construction. Although this type of joint is a common and basic way of connecting wooden elements into a frame, there is still a considerable interest in analyzing the existing and developing new forms of the tenon joint. A better understanding of specific mechanical properties of tenon joints can lead to improvement of quality of furniture frame structure.

There are numerous factors that affect the mechanical properties of loaded profileadhesive joints. The bending moment capacity of the window joints shows a statistically significant difference between bending moments for the tenon and dowel joints, and the absence of difference between the compression and tension for both joint types (Podlena et al. 2017). The factors that affect the moment capacity, and the main effects and interaction factors affecting the moment capacity for both compression and tension loads of the mortise and tenon joints have been investigated (Kasal et al. 2015). Tenon size (width and length) affects the bending moment capacity, and joint capacity is most affected by tenon length. In addition, shear strength of the wood parallel to grain has a substantial 
effect, while the adhesives have a measurable effect on the joint capacity.

The mortise and tenon furniture joins became stronger and stiffer as either tenon width or length increased. Tenon length has a greater effect on moment resistance, while tenon width has more effect on stiffness (Wilczyński and Warmbier 2003; Kasal et al. 2016). Mortise and tenon joints with tight-fitting shoulders have greater bending moment capacity than those with loose fitting shoulders; in addition, tenon shoulders substantially decrease rotation factors. Tenon cross-section also has a substantial effect on bending moment capacity. Joints with a round tenon configuration have only half of the capacity values of those with rectangular tenon configuration (Likos et al. 2012). The bending moment capacity is directly related to the depth of embedment of the tenons and strongly related to shoulder width, whereas tenon width have a lesser effect (Derikvand et al. 2014). Analysis of stiffness coefficients of mortise and tenon joints used on wooden window profiles confirmed that type of load did not affect the stiffness of the joint, but the width of joint did affect the stiffness (Podlena and Boruvka 2016). The effect of fitting for pairing of open full-width mortise and tenon joint elements on the compressive strength of the joint has been investigated. The mortise and tenon joints were found to be the strongest at a tight fit of $0.1 \mathrm{~mm}$ (Elek et al. 2020).

The results of investigation of the strength of the two most frequent joints in the upholstered furniture frames (mortise and tenon joints and double dowel joints), constructed with two wood species and the use of two adhesives (PVAc and PU) showed that the mortise and tenon joint in combination with PVAc, provided the best strength for all investigated wood species (Vassiliou et al. 2016). In an investigation of effect of wood species and adhesive type on the stiffness of rail to leg mortise and tenon furniture joints, the type of glue was not important for spruce joints, whereas for beech, the stiffness of joints glued with PVAc was significantly higher than with PU adhesive (Záborský et al. 2017). In comparison with PVAc, PU glue has appropriate strength, and, as they slightly expand during the hardening phase, can completely fill and cover the gaps between elements of joint (Hrovatin et al. 2013). Dowel joints glued with PU adhesive showed improved mechanical properties in humid environments (Máchová et al. 2019). The improved bonding properties of PVAc glue and bending and tension strength of the mortise and tenon joints has been achieved by using nano-fillers and its good dispersion provided at the low loadings of nano-fillers to PVAc matrix (Bardak et al. 2017).

Numerical methods, such as the 'finite element method', are applicable and effective for the analysis of orthotropic structures. The numerical results depend on simplifications and assumptions introduced in the numerical model. Numerical analyses give reasonable estimates of mechanical properties of wood constructions and their joints (Smardzewski 2008; Horman et al. 2010; Hajdarević and Martinović 2014; Hajdarević and Busuladžić 2015; Hu and Guan 2017; Hu et al 2019a, b).

This study investigated the effect of the tenon length on the mechanical properties of mortise tenon joints taken from a manufacturing process with two different joint geometry that were bonded by three glue types. In addition, the objective was to explore the capabilities of analytical and numerical calculation in design optimization of a frame joint. The strength and stiffness of the standard and double mortise and tenon joints were determined, and the results were compared by the simplified static expressions and numerical calculations of the linear-elastic model. 


\section{EXPERIMENTAL}

\section{Materials and Specimens}

The thirty-six (36) corners mortise and tenon joints that were supplied from furniture manufacturers (MS\&WOOD, Fojnica, Bosnia and Herzegovina) were analyzed (Fig. 1). All joints were made from beech wood (Fagus sylvatica L.), with round peg shape and mortise and tenon interference fit. The first set of joints contained 18 standard mortise and tenon joints with cross section of elements of $50 \times 30 \mathrm{~mm}$ (Fig. 1a), while the second set of joints contained 18 double mortise and tenon joints with cross section of elements $50 \times 40 \mathrm{~mm}$ and overhanging end (Fig. 1b). The joints were constructed by using two different tenon lengths $(20$ and $30 \mathrm{~mm}$ ), with 9 replications of each two joint sets. Two types of glue (PVAc and PU) were utilized for assembling the joint specimens. The three joints specimens, within each joint set and tenon length, were bonded with PVAc glue manufactured by AkzoNobel (PVAc1; Akzo Nobel N.V., Amsterdam, Netherlands) and by Kleiberit 303 D3 (PVAc2; Klebchemie, Weingarten, Germany). Three specimens were bonded with Jowat Power - PUR 687.40 glue (PU; Jowat SE, Detmold, Germany). The moisture content (MC) was evaluated in accordance with procedures describe in ISO 13061-1 (2014) after testing. The average MC value was $12.1 \%$.
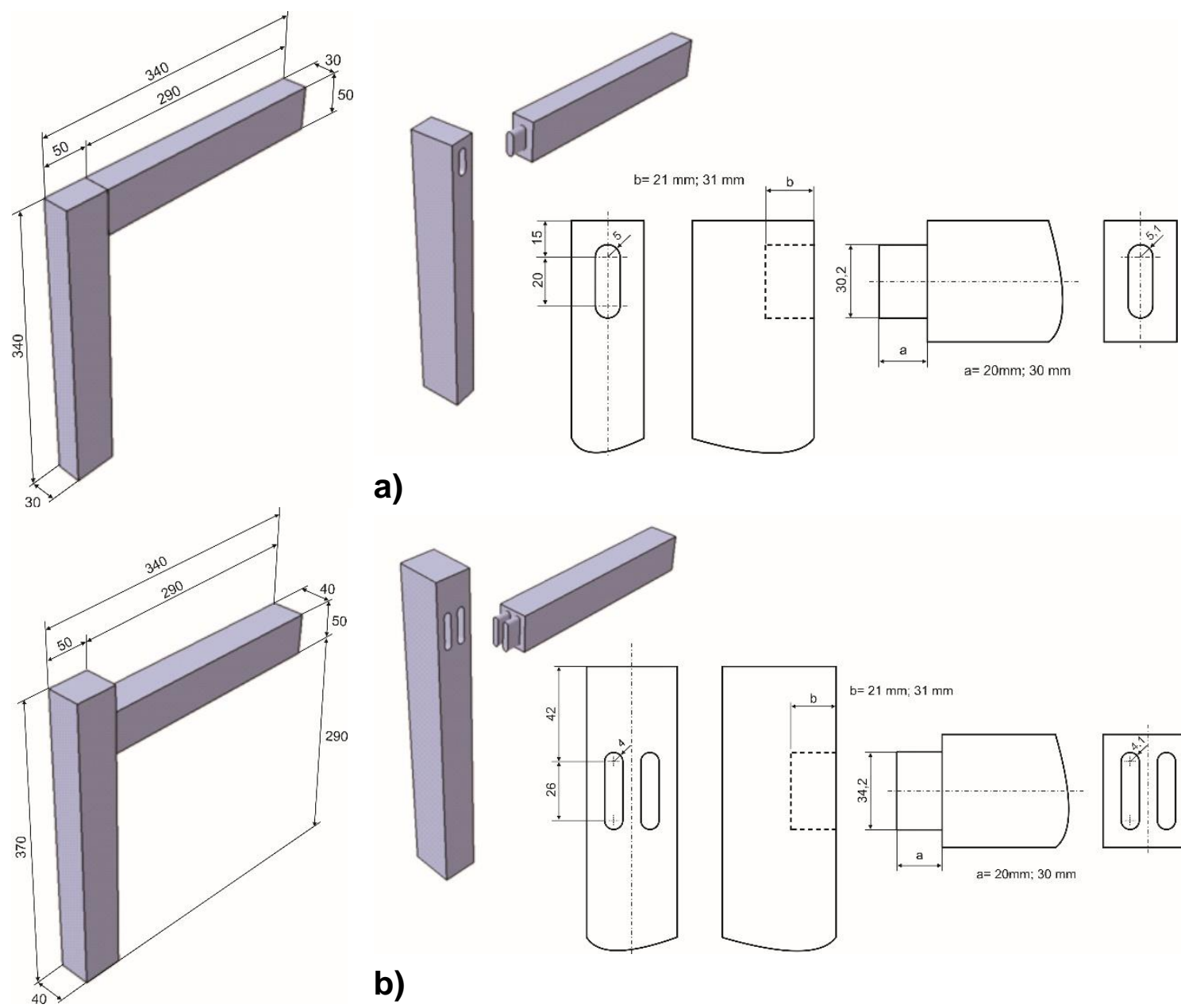

a)

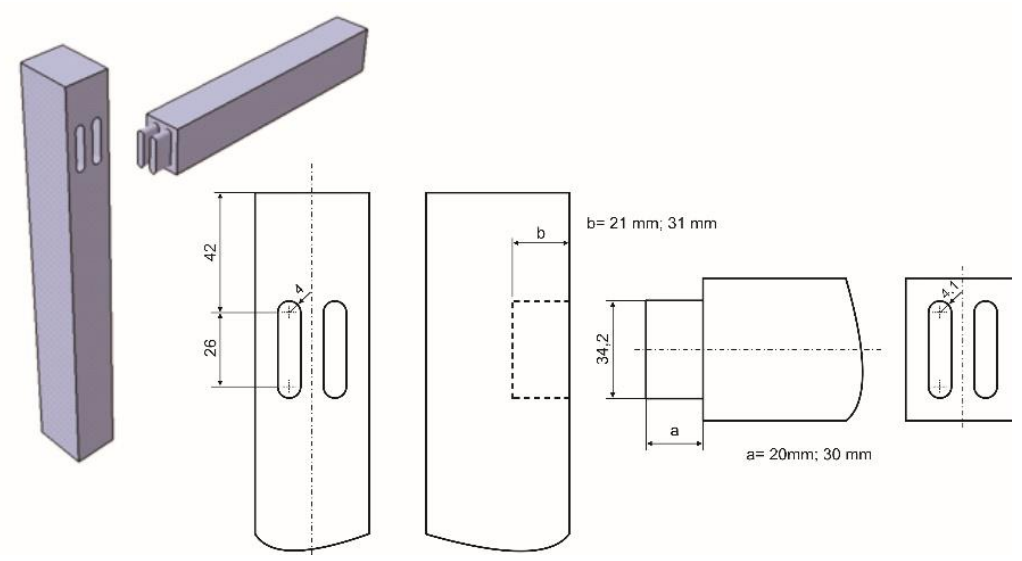

b)

Fig. 1. Test samples geometry: a) configuration of the standard mortise and tenon joints with two size of tenon lengths, b) configuration of the double mortise and tenon joints with overhanging end and two size of tenon lengths 


\section{Method of Testing}

The loading diagram of the joints is shown in Fig. 2a. The joint was pin connected on the lower edge. The roller support was set up on the upper joint edge. The load was applied to the joint in a manner that corresponded to compression of specimen. The test was carried out on a universal testing machine Zwick 1435 (Zwick Roell Group, Ulm, Germany), and the rate of static loading was $10 \mathrm{~mm} / \mathrm{min}$, Fig. 2b. The load value was continuously recorded by load cell RSCC-C3/1t (HBM, Darmstadt, Germany). The displacement of the defined point in the direction of the force $F$ during the testing was measured by inductive displacement transducer WI10 (HBM, Darmstadt, Germany). The force and the displacement along the force line were measured simultaneously until a large drop in the load occurred by data acquisition (DAQ) system QuantumX MX840B (HBM, Darmstadt, Germany). Display and processing of measurement results were performed using the DAQ software Catman (HBM, Darmstadt, Germany) The working diagrams of the tested specimens were created. Figure $2 \mathrm{c}$ shows the curve of force-displacement diagram with elastic region defined on the basis proportional forces $0.4 \cdot F_{\max }$ and $0.6 \cdot F_{\max }$ as well as the proportional limit point. Increased displacements that occurred at the beginning of loading were neglected in data analysis.

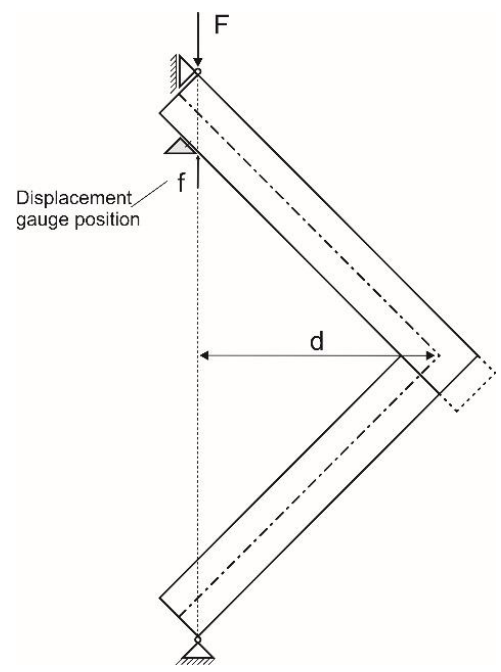

a)

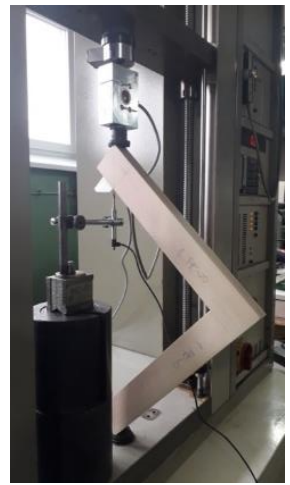

b)

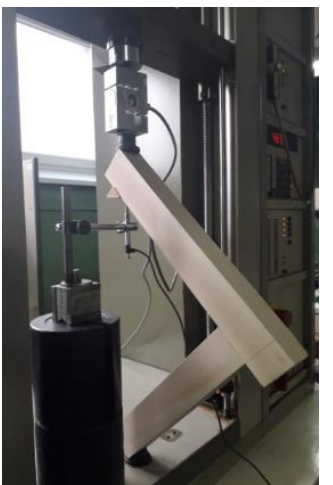

c)

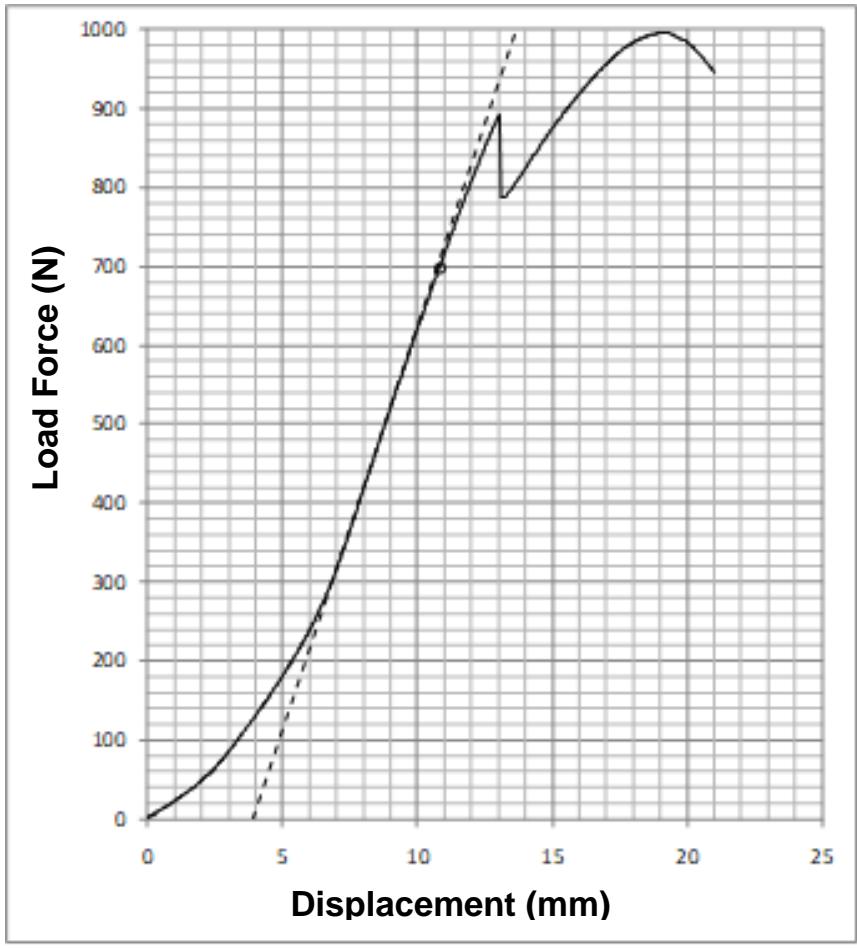

Fig. 2. Joints testing: a) the diagram of joint loading, b) set-up of standard and double mortise and tenon joints in the testing machine, $\mathrm{c}$ ) working diagram of joint strength testing 
The ultimate applied load values $\left(F_{\max }\right)$ and the load at the proportional limit $\left(F_{\mathrm{p}}\right)$ were ascertained using the software collected data. Corresponding bending moment values of the joints were calculated in Nm by expressions $M_{\max }=F_{\max } \cdot \mathrm{d}$ and $M_{\mathrm{p}}=F_{\mathrm{p}} \cdot \mathrm{d}$ for ultimate bending moment and bending moment at the proportional limit, respectively. The moment arm, the perpendicular distance from the force line to the point of intersection of symmetry axis of the elements, was $d=205.06 \mathrm{~mm}$ for both set of joints, as shown in Fig. 2a. The values of displacements at the ultimate applied load $\left(\delta_{\max }\right)$ and displacements at the proportional limit $\left(\delta_{\mathrm{p}}\right)$ were ascertained using the software collected data and were used for calculation of stiffness that was defined by ratios $F_{\max } / \delta_{\max }$ and $F_{\mathrm{p}} / \delta_{\mathrm{p}}$ for ultimate load and load at the proportional limit, respectively. The ratios were calculated in N/mm.

\section{Analytical Calculation of Joints Strength}

The strength of mortise and tenon joints was calculated by means of the common simplified static expressions to determine reaction moment of a loaded joint. Figure 3 presents a generalized scheme of analytical consideration of stress distribution on the characteristic support surface of tenon and tenon shoulder along with the required dimensions. The total reaction moment of a joint (1) is the sum of the simultaneous reaction moments obtained on the basis of defined stresses that occur on the characteristic support surfaces of the profile-adhesive joint, Fig. 3a,

$$
M_{R}=M_{1}+M_{2}+M_{3}
$$

where $M_{\mathrm{R}}$ is total reaction moment, $M_{1}$ is moment of the edge cheek, $M_{2}$ is moment of the structural shoulder and $M_{3}$ is moment of the face cheek.

Reaction moments were calculated using the joint dimensions, the number of glue lines and relevant stress (permissible stress or strength of used material), Fig. 3b.
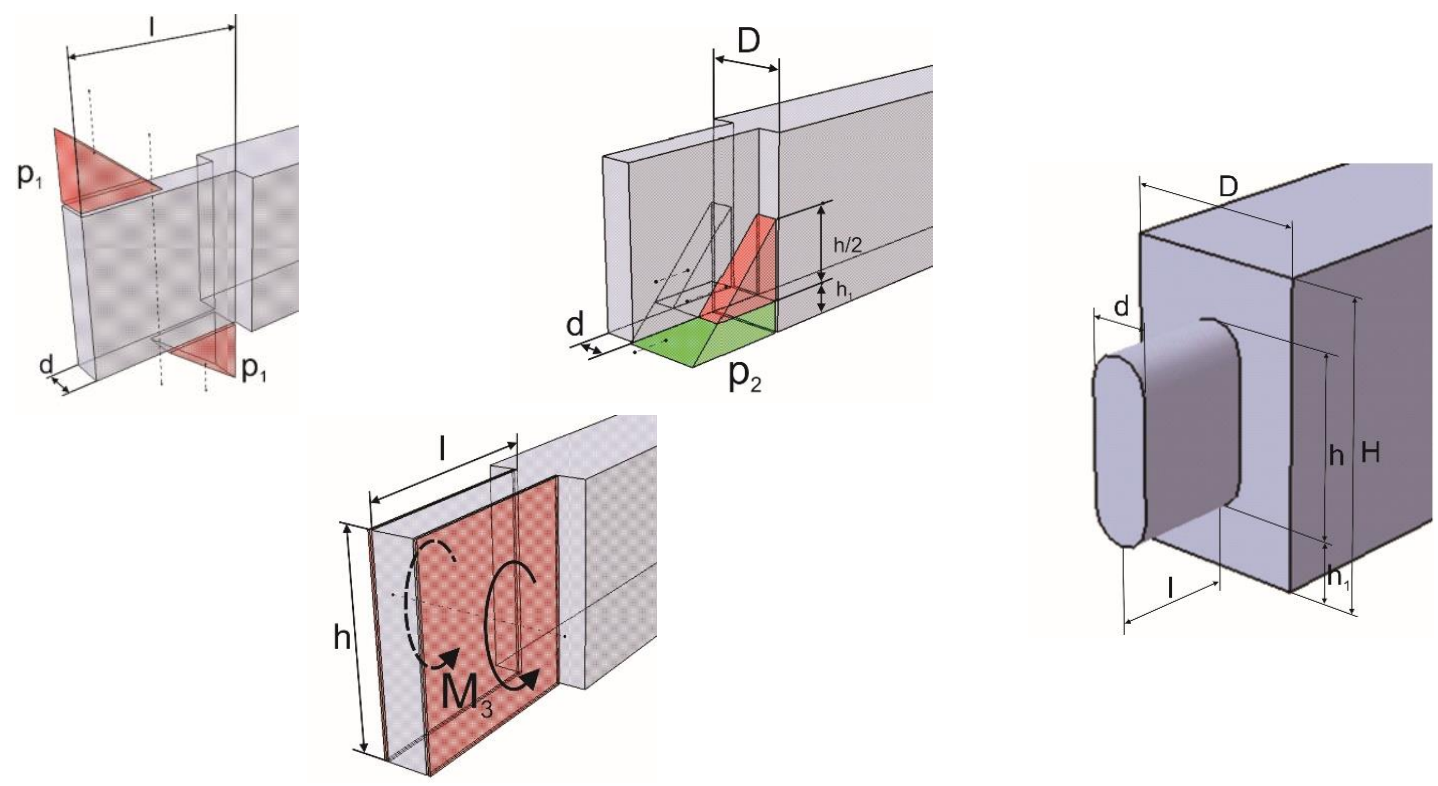

a)

b)

Fig. 3. Reaction moments of a loaded joint: a) generalized scheme of stress distribution on the characteristic support surfaces, b) relevant dimensions of standard and double mortise and tenon joints 
The moment of the edge cheek $M_{1}$ and the reaction moment of structural shoulder $M_{2}$ were obtained by the following equations,

$$
\begin{aligned}
& M_{1}=\sigma_{1} \frac{l^{2} d}{6} \\
& M_{2}=\frac{\sigma_{2}}{3}\left[\left(\frac{h}{2}+h_{1}\right)^{2} D-\frac{\left(\frac{h}{2}\right)^{3}}{\left(\frac{h}{2}+h_{1}\right)} d\right]
\end{aligned}
$$

where $\sigma_{1}$ and $\sigma_{2}$ are negative normal stress i.e. compression strength of wood normal to the fibers $(\mathrm{Pa})$, and other notations are shown in Fig. 3b. Moment in the plane of face cheek $M_{3}$ was obtained by Eq. 3,

$$
M_{3}=n \beta h l^{2} \tau
$$

where $n$ is the number of face cheeks, $\tau$ is shear stress i.e. strength of glue line (Pa), $\beta$ is the Saint-Venant coefficient shown in Eq. 5,

$$
\frac{1}{\beta}=3+\frac{2,6}{0,45+\frac{h}{1}}
$$

where dimensions $h$ and $l$ are tenon width and tenon length.

\section{Numerical Analysis of Joints}

The total reactive moments of joints obtained from analytical calculation were used in a simplified numerical analysis of stress and strain of the loaded joints. The physical model is defined based on the experimental loading diagram of the joints and local coordinates are used to define the grain directions of the joint elements, as shown in Fig. 4. Loading forces $\left(F_{l}\right)$ of each model of joints were calculated by the equation $F_{l}=M_{\mathrm{R}} / d$ where $M_{\mathrm{R}}$ is analytical total reaction moment and $d$ is the moment arm.

a)

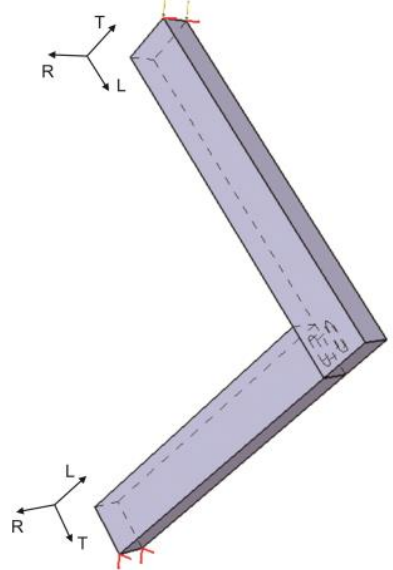

b)

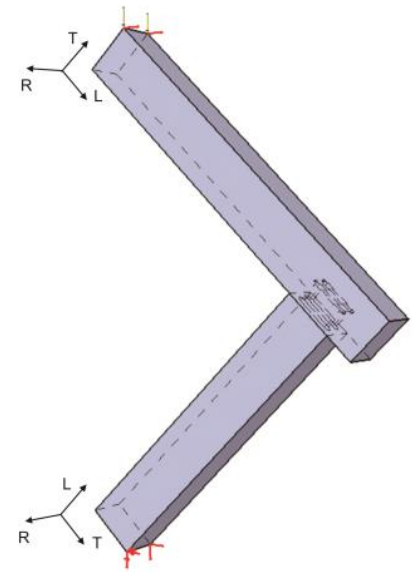

Fig. 4. The physical model of the joints: a) standard mortise and tenon joint (tenon length 20 $\mathrm{mm}$ ), b) double mortise and tenon joint (tenon length $20 \mathrm{~mm}$ )

Numerical 3D linear-elastic model for orthotropic material was solved by a method based on the finite elements. Mesh model of standard mortise and tenon joint, along with mesh details of standard and double tenon joints are shown in Fig. 5. The 10-node parabolic tetrahedron finite element was used to create numerical model. The mesh was selectively refined to obtain a better results accuracy. A fastened connection was modeled between 
surfaces of mortise and tenon while among other surfaces i.e. tenon shoulder and mortise side wall a contact connection was used. Calculation was carried out for beech wood and the elastic properties of the wood are presented in Table 1 (Smardzewski 2008). Adhesive, i.e., glue line and interference fit were neglected. The numerical results were obtained using the CAD/CAM/CAE system CATIA (Dassault Systemes SE, Velizy-Villacoublay, France).

a)

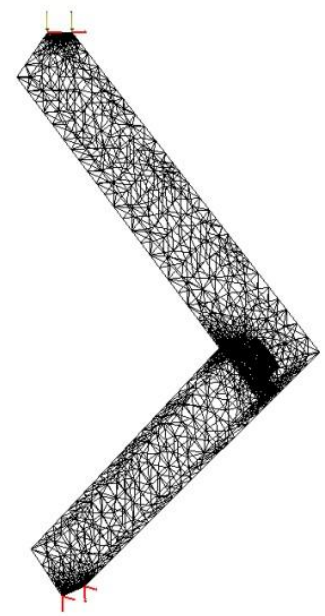

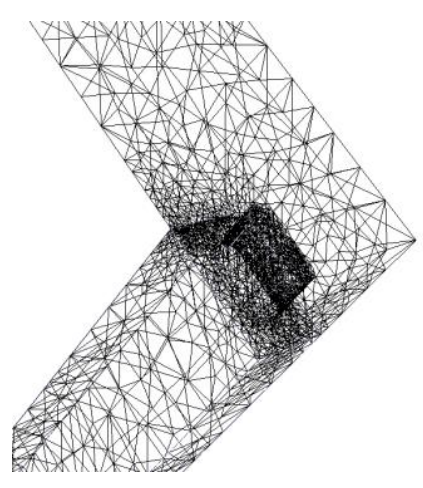

b)

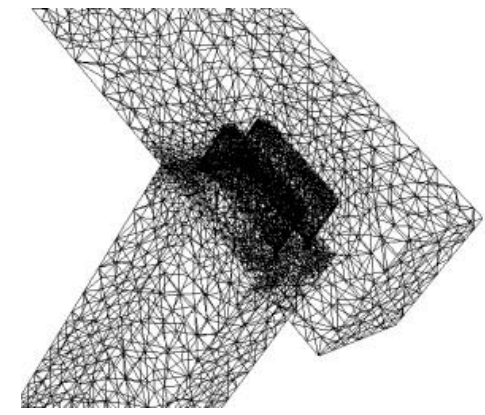

Fig. 5. Numerical models of the joints: a) mesh of standard mortise and tenon joint with boundary conditions (tenon length $20 \mathrm{~mm}$ ), b) details of standard and double mortise and tenon joints mesh (tenon length $20 \mathrm{~mm}$ )

Table 1. Elastic Properties of Beech Wood (Smardzewski 2008)

\begin{tabular}{|c|c|c|c|c|c|c|c|c|c|c|c|}
\hline \multicolumn{4}{|c|}{$\begin{array}{c}\text { Modulus of Elasticity } \\
(\mathrm{GPa})\end{array}$} & \multicolumn{3}{c|}{$\begin{array}{c}\text { Modulus of Rigidity } \\
\text { (GPa) }\end{array}$} & \multicolumn{6}{c|}{ Poisson's Ratio } \\
\hline$E_{\mathrm{L}}$ & $E_{\mathrm{R}}$ & $E_{\mathrm{T}}$ & $\mathrm{G} \mathrm{LR}$ & $\mathrm{G} \mathrm{LT}$ & $G_{\mathrm{RT}}$ & $v_{\mathrm{LR}}$ & $v_{\mathrm{LT}}$ & $v_{\mathrm{RT}}$ & $v_{\mathrm{TR}}$ & $v_{\mathrm{RL}}$ & $v_{\mathrm{TL}}$ \\
\hline 13.96 & 2.28 & 1.16 & 1.64 & 1.08 & 0.47 & 0.45 & 0.51 & 0.75 & 0.36 & 0.07 & 0.04 \\
9 & 4 & 0 & 5 & 2 & 1 & 0 & 0 & 0 & 0 & 5 & 4 \\
\hline
\end{tabular}

\section{RESULTS AND DISCUSSION}

The experimental results of maximal $\left(F_{\max }\right)$ and proportional force $\left(F_{\mathrm{p}}\right)$, maximal moment $\left(M_{\max }\right)$ and proportional moment $\left(M_{\mathrm{p}}\right)$ and ratio of proportional and maximal moment $\left(M_{\mathrm{p}} / M_{\max }\right)$ of the standard tenon joints and double tenon joints with two different tenon lengths are given in Tables 2 and 3, respectively.

Generally, the results indicated that average bending moment (both maximum moment and proportional moment) of standard tenon joints and double tenon joints and for all investigated types of glue increased as the tenon length increased. Also, the results show relatively large differences among the average bending moment and the average proportional moments of mortise and tenon joints bonded by PVAc1, PVAc2, and PU. The differences are the results of a high slope of the proportional lines that have been fitted to the curves of force-displacement relationship in order to neglect the initial large displacements that occurred at the beginning of loading. 
Table 2. Experimental Results of Forces and Bending Moments of the Standard Mortise and Tenon Joints

\begin{tabular}{|c|c|c|c|c|c|c|c|c|c|c|c|c|c|}
\hline \multicolumn{14}{|c|}{ Standard mortise and tenon joint } \\
\hline \multicolumn{7}{|c|}{ Tenon length $20 \mathrm{~mm}$} & \multicolumn{7}{|c|}{ Tenon length $30 \mathrm{~mm}$} \\
\hline$\frac{\stackrel{0}{2}}{\sqrt{0}}$ & 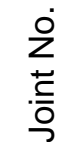 & $\begin{array}{c}F_{\max } \\
(\mathrm{N})\end{array}$ & $\begin{array}{c}F_{\mathrm{p}} \\
(\mathrm{N})\end{array}$ & $\begin{array}{c}M_{\max } \\
(\mathrm{Nm})\end{array}$ & $\begin{array}{c}M_{p} \\
(\mathrm{Nm})\end{array}$ & $\begin{array}{c}M_{\mathrm{p}} / \\
M_{\max }\end{array}$ & $\frac{0}{\frac{0}{N}}$ & $\begin{array}{l}\text { i } \\
\text { z. } \\
\text {. }\end{array}$ & $\begin{array}{c}F_{\max } \\
(\mathrm{N})\end{array}$ & $\begin{array}{c}F_{\mathrm{p}} \\
(\mathrm{N})\end{array}$ & $\begin{array}{c}M_{\max } \\
(\mathrm{Nm})\end{array}$ & $\begin{array}{c}M_{p} \\
(\mathrm{Nm})\end{array}$ & $\begin{array}{l}M_{\mathrm{p}} / \\
M_{\max }\end{array}$ \\
\hline \multirow{4}{*}{$\stackrel{\bar{s}}{\stackrel{0}{\Delta}}$} & 1 & 995.45 & 697.96 & 204.13 & 143.12 & 0.70 & \multirow{4}{*}{ 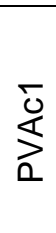 } & 1 & 1405.77 & 952.42 & 288.27 & 195.30 & 0.68 \\
\hline & 2 & 1311.22 & 873.19 & 268.88 & 179.06 & 0.67 & & 2 & 1439.13 & 831.90 & 295.11 & 170.59 & 0.58 \\
\hline & 3 & 1091.08 & 824.77 & 223.74 & 169.13 & 0.76 & & 3 & 1398.14 & 936.65 & 286.70 & 192.07 & 0.67 \\
\hline & 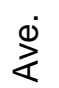 & 1132.58 & 798.64 & 232.25 & 163.77 & 0.71 & & 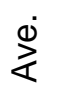 & 1414.35 & 906.99 & 290.03 & 185.99 & 0.64 \\
\hline \multirow{4}{*}{ 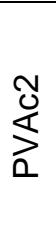 } & 1 & 865.23 & 730.86 & 177.42 & 149.87 & 0.84 & \multirow{4}{*}{ 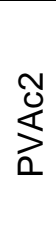 } & 1 & 1198.14 & 796.42 & 245.69 & 163.31 & 0.66 \\
\hline & 2 & 1023.00 & 708.50 & 209.78 & 145.29 & 0.69 & & 2 & - & - & - & - & - \\
\hline & 3 & 1058.32 & 835.19 & 217.02 & 171.26 & 0.79 & & 3 & 1186.53 & 754.98 & 243.31 & 154.82 & 0.64 \\
\hline & 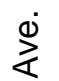 & 982.18 & 758.18 & 201.41 & 155.47 & 0.77 & & 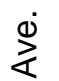 & 1192.34 & 775.70 & 244.50 & 159.07 & 0.65 \\
\hline \multirow{4}{*}{$\stackrel{\supset}{\alpha}$} & 1 & 1271.22 & 872.90 & 260.68 & 179.00 & 0.69 & \multirow{4}{*}{$\stackrel{\supset}{\alpha}$} & 1 & 1471.94 & 956.35 & 301.84 & 196.11 & 0.65 \\
\hline & 2 & 1001.60 & 704.96 & 205.39 & 144.56 & 0.70 & & 2 & 1563.66 & 956.03 & 320.64 & 196.04 & 0.61 \\
\hline & 3 & 1010.29 & 716.30 & 207.17 & 146.88 & 0.71 & & 3 & 1552.99 & 1081.09 & 318.46 & 221.69 & 0.70 \\
\hline & 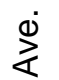 & 1094.37 & 764.72 & 224.41 & 156.81 & 0.70 & & $\stackrel{\bigotimes}{\stackrel{\alpha}{\alpha}}$ & 1529.53 & 997.82 & 313.65 & 204.61 & 0.65 \\
\hline
\end{tabular}


Table 3. Experimental Results of Forces and Bending Moments of the Double Mortise and Tenon Joints

\begin{tabular}{|c|c|c|c|c|c|c|c|c|c|c|c|c|c|}
\hline \multicolumn{14}{|c|}{ Double mortise and tenon joint } \\
\hline \multicolumn{7}{|c|}{ Tenon length $20 \mathrm{~mm}$} & \multicolumn{7}{|c|}{ Tenon length $30 \mathrm{~mm}$} \\
\hline$\frac{\stackrel{0}{2}}{0}$ & 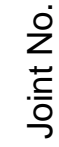 & $\begin{array}{c}F_{\max } \\
(\mathrm{N})\end{array}$ & $\begin{array}{c}F_{\mathrm{p}} \\
(\mathrm{N})\end{array}$ & $\begin{array}{r}M_{\max } \\
(\mathrm{Nm})\end{array}$ & $\begin{array}{c}M_{p} \\
(\mathrm{Nm})\end{array}$ & $\begin{array}{c}M_{\mathrm{p}} / \\
M_{\max }\end{array}$ & $\frac{\frac{0}{3}}{0}$ & 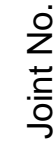 & $\begin{array}{c}F_{\max } \\
(\mathrm{N})\end{array}$ & $\begin{array}{c}F_{\mathrm{p}} \\
(\mathrm{N})\end{array}$ & $\begin{array}{c}M_{\max } \\
(\mathrm{Nm})\end{array}$ & $\begin{array}{c}M_{\mathrm{p}} \\
(\mathrm{Nm})\end{array}$ & $\begin{array}{l}M_{\mathrm{p}} / \\
M_{\text {max }}\end{array}$ \\
\hline \multirow{4}{*}{ 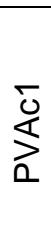 } & 1 & 1708.84 & 1049.56 & 350.42 & 215.22 & 0.61 & \multirow{4}{*}{$\sum_{0}^{\overline{0}}$} & 1 & 1638.84 & 1073.75 & 336.06 & 220.18 & 0.66 \\
\hline & 2 & 1485.43 & 913.02 & 304.60 & 187.22 & 0.61 & & 2 & 1842.31 & 1189.43 & 377.78 & 243.91 & 0.65 \\
\hline & 3 & 1830.14 & 1162.95 & 375.29 & 238.47 & 0.64 & & 3 & 2479.71 & 1453.86 & 508.49 & 298.13 & 0.59 \\
\hline & 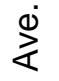 & 1674.80 & 1041.84 & 343.43 & 213.64 & 0.62 & & 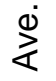 & 1986.95 & 1239.01 & 407.44 & 254.07 & 0.62 \\
\hline \multirow{4}{*}{ 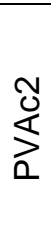 } & 1 & 1902.34 & 1286.61 & 390.09 & 263.83 & 0.68 & \multirow{4}{*}{ 令 } & 1 & 2098.28 & 1315.27 & 430.27 & 269.71 & 0.63 \\
\hline & 2 & 1766.90 & 1099.59 & 362.32 & 225.48 & 0.62 & & 2 & 2022.27 & 1279.31 & 414.69 & 262.33 & 0.63 \\
\hline & 3 & 1879.69 & 1156.01 & 385.45 & 237.05 & 0.61 & & 3 & 1660.90 & 1235.61 & 340.58 & 253.37 & 0.74 \\
\hline & 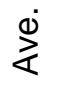 & 1849.64 & 1180.74 & 379.29 & 242.12 & 0.64 & & 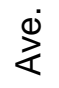 & 1927.15 & 1276.73 & 395.18 & 261.81 & 0.66 \\
\hline \multirow{4}{*}{ 곰 } & 1 & 1621.02 & 1105.05 & 332.41 & 226.60 & 0.68 & \multirow{4}{*}{$\stackrel{\supset}{\square}$} & 1 & 2268.87 & 1649.37 & 465.25 & 338.22 & 0.73 \\
\hline & 2 & 1142.50 & 692.42 & 234.28 & 141.99 & 0.61 & & 2 & 1806.83 & 1229.71 & 370.51 & 252.16 & 0.68 \\
\hline & 3 & 1572.69 & 973.29 & 322.50 & 199.58 & 0.62 & & 3 & 2202.59 & 1308.32 & 451.66 & 268.28 & 0.59 \\
\hline & 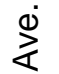 & 1445.40 & 923,59 & 296.39 & 189.39 & 0.64 & & 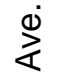 & 2092.76 & 1395.80 & 429.14 & 286.22 & 0.67 \\
\hline
\end{tabular}


The standard mortise and tenon joints glued with PVAc2 had the lowest average bending moment $(201.4 \mathrm{Nm}, 244.5 \mathrm{Nm})$ and average proportional moments $(155.5 \mathrm{Nm}$, $159.1 \mathrm{Nm}$ ) for tenon length $20 \mathrm{~mm}$ and $30 \mathrm{~mm}$, respectively. The joints glued with PVAc1 for tenon length $20 \mathrm{~mm}$ and the joints glued with PU for tenon length $30 \mathrm{~mm}$ had the highest average bending moment and proportional moment. The maximal bending moment (average value) increased by 24.9\% (PVAc1), 21.4\% (PVAc2) and 39.8\% (PU) as tenon length increased from $20 \mathrm{~mm}$ to $30 \mathrm{~mm}$ for standard mortise and tenon joint. The joints with tenon length $30 \mathrm{~mm}$ had $13.6 \%$ (PVAc1), 2.3\% (PVAc2) and 30.9\% (PU) higher proportional bending moments (average value) than the joints with tenon length $20 \mathrm{~mm}$. Normalized ratios of average values of proportional and maximal moment of the standard tenon joints with tenon length $20 \mathrm{~mm}$ were 71\% (PVAc1), 77\% (PVAc2) and 70\% (PU). These percentages were lower for the standard tenon joints with tenon length $30 \mathrm{~mm}$ and those percentages are 64\% (PVAc1), 65\% (PVAc2) and 65\% (PU).

The double mortise and tenon joints glued with PU had the lowest average bending moment $(296.4 \mathrm{Nm})$ and average proportional moment $(189.4 \mathrm{Nm})$ for tenon length $20 \mathrm{~mm}$ and also had the highest average bending moment $(429.1 \mathrm{Nm})$ and average proportional moment $(286.2 \mathrm{Nm})$ for tenon length $30 \mathrm{~mm}$. The maximal bending moment of double mortise and tenon joints with tenon length $30 \mathrm{~mm}$ were $18.6 \%$ (PVAc1), 4.2\% (PVAc2) and $44.8 \%$ (PU) higher than the average value for the double tenon joints with tenon length $20 \mathrm{~mm}$. The average proportional moment increased by $18.9 \%$ (PVAc1), 8.1\% (PVAc2) and $51.1 \%(\mathrm{PU})$ as tenon length increased from $20 \mathrm{~mm}$ to $30 \mathrm{~mm}$ for double mortise and tenon joint. The percentages of the average ratio of proportional and maximal moments of the double tenon joints with tenon length $20 \mathrm{~mm}$ were 62\% (PVAc1), 64\% (PVAc2) and 64\% (PU), while they were 62\% (PVAc1), 66\% (PVAc2) and 67\% (PU) for the double tenon joints with tenon length $30 \mathrm{~mm}$.

The differences between the average value of maximum moment (bending moment capacities) of standard tenon joints and double tenon joints were clearly observed. However, these values were not comparable due to the dimensional differences of these two types of joints (thickness and width of tenon and thickness of joint elements). The presented experimental results are unable to determine the dimensional effect on the joints maximum bending moment. Also, the characteristic patterns of fractures of certain types of joints were not observed. Wood fracture of the joint member, tenon fracture or tenon pulled out from the member, as glue line failed and the tenon started to take the load, occurred in all sets of standard and double joints, as shown in Fig. 6.

a)

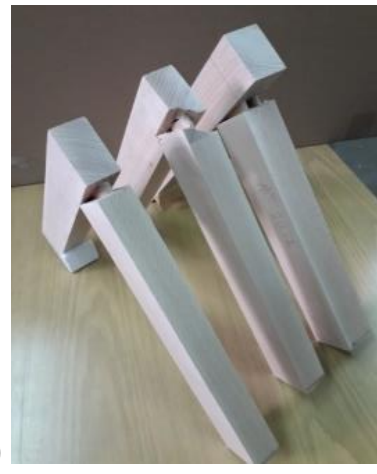

b)

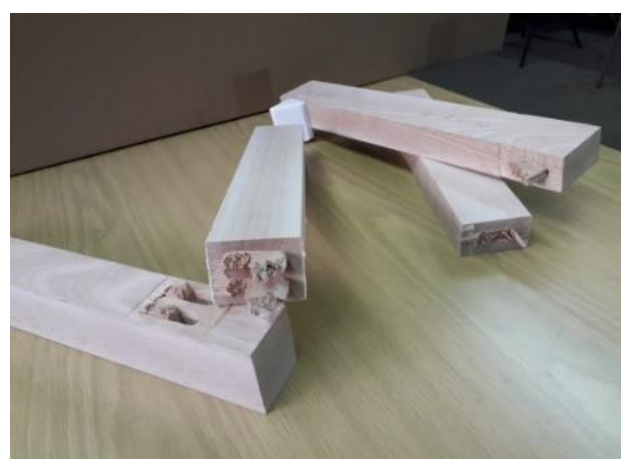

Fig. 6. Type of standard and double joints failures: a) tenons pull out from the members after the glue line fractured and the fracture of wood of a joint member, $b$ ) the fracture of joints tenons 
The analytical calculation results of the reaction moments, total reaction moment $M_{\mathrm{R}}$, and ratio of total reaction moment for tenon lengths $20 \mathrm{~mm}$ and tenon lengths $30 \mathrm{~mm}$ of the standard and double tenon joints are given in Table 4. The compression strength of beech wood normal to the fibers (negative normal stresses $\sigma_{1}$ and $\sigma_{2}$ ) and the generalized strength of a glue line (shear stress) that was used in the calculation was $10 \mathrm{MPa}$ (Skarvelis and Mantanis 2013; Derikvand and Pangh 2016).

Table 4. Analytical Calculation of Reaction Moments of Standard and Double Tenon Joints

\begin{tabular}{|c|c|c|c|c|}
\hline \multirow{2}{*}{$\begin{array}{c}\text { Reaction } \\
\text { moments } \\
(\mathrm{Nm})\end{array}$} & \multicolumn{2}{|c|}{ Standard mortise and tenon joint } & \multicolumn{2}{c|}{ Double mortise and tenon joint } \\
\cline { 2 - 5 } & $20 \mathrm{~mm}$ & $30 \mathrm{~mm}$ & $20 \mathrm{~mm}$ & $30 \mathrm{~mm}$ \\
\hline$M_{1}$ & 6.80 & 15.30 & 5.47 & 12.30 \\
\hline$M_{2}$ & 57.82 & 57.82 & 72.40 & 72.40 \\
\hline$M_{3}$ & 55.84 & 113.61 & 130.20 & 265.62 \\
\hline$M_{\mathrm{R}}$ & 120.46 & 186.73 & 208.07 & 350.32 \\
\hline$M_{\mathrm{R} 20} / M_{\mathrm{R} 30}$ & \multicolumn{3}{c}{0.59} \\
\hline
\end{tabular}

Table 5. Ratio of Calculated Reaction Moments and Experimental Moments of Standard and Double Tenon Joints

\begin{tabular}{|c|c|c|c|c|c|c|c|c|c|}
\hline \multicolumn{5}{|c|}{ Standard mortise and tenon joint } & \multicolumn{5}{|c|}{ Double mortise and tenon joint } \\
\hline \multirow{3}{*}{ 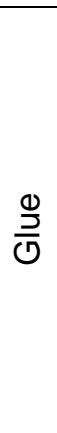 } & \multicolumn{4}{|c|}{ Tenon length } & \multirow{3}{*}{$\frac{\frac{0}{3}}{\frac{D}{N}}$} & \multicolumn{4}{|c|}{ Tenon length } \\
\hline & $20 r$ & & 30 & & & 20 & & 30 & \\
\hline & $M_{\mathrm{R}} / M_{\max }$ & $M \mathrm{R} / M_{\mathrm{P}}$ & $M_{\mathrm{R}} / M_{\max }$ & $M_{\mathrm{R}} / M_{\mathrm{P}}$ & & $M_{\mathrm{R}} / M_{\max }$ & $M \mathrm{R} / M_{\mathrm{P}}$ & $M_{\mathrm{R}} / M_{\max }$ & $M_{\mathrm{R}} / M_{\mathrm{P}}$ \\
\hline$\underset{\square}{\overline{0}}$ & 0.52 & 0.74 & 0.64 & 1.00 & 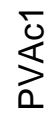 & 0.61 & 0.97 & 0.86 & 1.38 \\
\hline 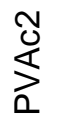 & 0.60 & 0.77 & 0.76 & 1.17 & 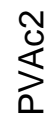 & 0.55 & 0.86 & 0.89 & 1.34 \\
\hline$\stackrel{\partial}{\Lambda}$ & 0.54 & 0.77 & 0.60 & 0.91 & $\stackrel{2}{\square}$ & 0.70 & 1.1 & 0.82 & 1.22 \\
\hline
\end{tabular}

The moment of the edge cheek $M_{1}$ and the reactive moment in the plane of the face cheek $M_{3}$ for tenon length $20 \mathrm{~mm}$ were $55.5 \%$ and $50.9 \%$ lower than the value for joints with tenon length $30 \mathrm{~mm}$ for both standard and double joints, respectively. Apparently, the value of the reaction moment of structural shoulder $M_{2}$ did not change. The percentages of 
the ratio of total reaction moment for tenon lengths $20 \mathrm{~mm}$ and tenon lengths $30 \mathrm{~mm}$ were $65 \%$ and $59 \%$ for the standard tenon joints and for the double tenon joints, respectively.

The ratio of calculated total reaction moments and experimental moments for the standard and double tenon joints and tenon lengths 20 and $30 \mathrm{~mm}$ are given in Table 5. The results indicated that the reactive moment obtained by the analytical calculation does not represent the value of the bending moment capacities of joint. The reactive moment can be taken as the estimated value of the proportional moment of the loaded joint.

The total reaction moments were no higher than bending moment capacities. The percentages of the ratio of total reaction moments and average maximum moments (bending moment capacities) for tenon lengths $20 \mathrm{~mm}$ were ranged from $52 \%$ to $60 \%$ for the standard tenon joints and from 55\% to $70 \%$ for the double tenon joints. The percentages of the same ratio for tenon lengths $30 \mathrm{~mm}$ were higher and ranged from $60 \%$ to $76 \%$ for the standard tenon joints and from $82 \%$ to $89 \%$ for the double tenon joints.

In general, the total reaction moments were lower than proportional moments for tenon length $20 \mathrm{~mm}$ or higher than proportional moments for tenon length $30 \mathrm{~mm}$. The exception were some joints glued with PU. The percentages of the ratio of total reaction moments and proportional moments for tenon lengths $20 \mathrm{~mm}$ were ranged from $74 \%$ to $77 \%$ for the standard tenon joints and from $86 \%$ to $110 \%$ for the double tenon joints. The percentages of the same ratio for tenon lengths $30 \mathrm{~mm}$ were higher and were ranged from $91 \%$ to $117 \%$ for the standard tenon joints and from $122 \%$ to $138 \%$ for the double tenon joints.

Table 6. Experimental Results of Displacements and the Ratios of Forces and Displacements of the Standard Mortise and Tenon Joints

\begin{tabular}{|c|c|c|c|c|c|c|c|c|c|c|c|}
\hline \multicolumn{12}{|c|}{ Standard mortise and tenon joint } \\
\hline \multicolumn{6}{|c|}{ Tenon length $20 \mathrm{~mm}$} & \multicolumn{6}{|c|}{ Tenon length $30 \mathrm{~mm}$} \\
\hline$\frac{0}{\frac{D}{0}}$ & $\begin{array}{l}\stackrel{0}{2} \\
\text { : } \\
\text { 음 }\end{array}$ & $\begin{array}{l}\delta_{\max } \\
(\mathrm{mm})\end{array}$ & $\begin{array}{c}F_{\max } / \\
\delta_{\max } \\
(\mathrm{N} / \mathrm{mm})\end{array}$ & $\begin{array}{c}\delta_{\mathrm{p}} \\
(\mathrm{mm})\end{array}$ & $\begin{array}{c}F_{\mathrm{p}} / \delta_{\mathrm{p}} \\
(\mathrm{N} / \mathrm{mm})\end{array}$ & $\frac{\stackrel{0}{二}}{\mathrm{~N}}$ & 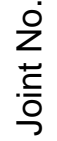 & $\begin{array}{c}\delta_{\max } \\
(\mathrm{mm})\end{array}$ & $\begin{array}{c}F_{\max } / \\
\delta_{\max } \\
(\mathrm{N} / \mathrm{mm})\end{array}$ & $\begin{array}{c}\delta_{p} \\
(\mathrm{~mm})\end{array}$ & $\begin{array}{c}F_{\mathrm{p}} / \delta_{\mathrm{p}} \\
(\mathrm{N} / \mathrm{mm})\end{array}$ \\
\hline \multirow{4}{*}{$\frac{0}{3}$} & 1 & 19.04 & 52.28 & 10.81 & 64.57 & \multirow{4}{*}{$\sum_{0}^{\overline{0}}$} & 1 & 23.67 & 59.39 & 13.72 & 69.42 \\
\hline & 2 & 17.04 & 76.97 & 11.47 & 76.13 & & 2 & 22.46 & 64.08 & 9.42 & 88.31 \\
\hline & 3 & 14.55 & 74.99 & 11.41 & 72.28 & & 3 & 22.05 & 63.41 & 11.30 & 82.89 \\
\hline & 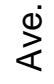 & 16.87 & 68.08 & 11.23 & 70.99 & & $\stackrel{1}{<}^{\infty}$ & 22.73 & 62.29 & 11.48 & 80.21 \\
\hline \multirow{4}{*}{ 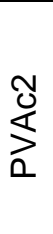 } & 1 & 17.60 & 49.16 & 12.57 & 58.17 & \multirow{4}{*}{$\overbrace{0}^{N}$} & 1 & 22.16 & 54.07 & 13.47 & 59.15 \\
\hline & 2 & 20.77 & 49.26 & 11.25 & 62.98 & & 2 & - & - & - & - \\
\hline & 3 & 18.29 & 57.87 & 12.31 & 67.87 & & 3 & 21.35 & 55.57 & 8.95 & 84.31 \\
\hline & 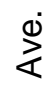 & 18.89 & 52.09 & 12.04 & 63.01 & & 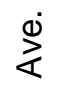 & 21.76 & 54.82 & 11.21 & 71.73 \\
\hline \multirow{4}{*}{$\vec{a}$} & 1 & 19.14 & 66.42 & 12.81 & 68.16 & \multirow{4}{*}{$\stackrel{\supset}{a}$} & 1 & 22.53 & 65.32 & 12.77 & 74.88 \\
\hline & 2 & 14.25 & 70.28 & 8.92 & 79.01 & & 2 & 24.17 & 64.68 & 13.38 & 71.46 \\
\hline & 3 & 16.04 & 63.00 & 10.44 & 68.61 & & 3 & 24.85 & 62.48 & 15.68 & 68.96 \\
\hline & 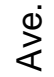 & 16.47 & 66.57 & 10.72 & 71.93 & & 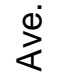 & 23.85 & 64.16 & 13.94 & 71.77 \\
\hline
\end{tabular}


The values of displacements at the ultimate applied load $\left(\delta_{\max }\right)$, displacements at the proportional limit $\left(\delta_{\mathrm{p}}\right)$ and ratios $F_{\max } / \delta_{\max }$ and $F_{\mathrm{p}} / \delta_{\mathrm{p}}$ for the standard and double tenon joints and tenon lengths 20 and $30 \mathrm{~mm}$ are given in Tables 6 and 7, respectively.

The percentages of the average ratio of proportional and maximal displacement of the standard tenon joints with tenon length $20 \mathrm{~mm}$ were approximately $66 \%$, while this ratio percentage was from $51 \%$ to $58 \%$ for all other joints sets.

The ratios of forces at the ultimate applied load and displacement at the ultimate applied load was less than the same ratio at the proportional limit for both joint types and both tenon lengths, i.e., the joints stiffness was higher for the load below the proportional limit. The double mortise and tenon joints glued with PU and tenon length $30 \mathrm{~mm}$ had the highest average values of joints stiffness $(92.3 \mathrm{~N} / \mathrm{mm}$ at ultimate applied load and 118.4 $\mathrm{N} / \mathrm{mm}$ at the proportional limit). The standard mortise and tenon joints glued with PVAc2 and with tenon length $20 \mathrm{~mm}$ had the lowest average joints stiffness at the ultimate applied load $(52.1 \mathrm{~N} / \mathrm{mm})$ and at the proportional limit $(63.0 \mathrm{~N} / \mathrm{mm})$. The presented results are not able to determine the effect of tenon length and glue types on the joints stiffness.

Table 7. Experimental Results of Displacements and the Ratios of Forces and Displacements of the Double Mortise and Tenon Joints

\begin{tabular}{|c|c|c|c|c|c|c|c|c|c|c|c|}
\hline \multicolumn{12}{|c|}{ Double mortise and tenon joint } \\
\hline \multicolumn{6}{|c|}{ Tenon length $20 \mathrm{~mm}$} & \multicolumn{6}{|c|}{ Tenon length $30 \mathrm{~mm}$} \\
\hline$\frac{\stackrel{0}{2}}{0}$ & 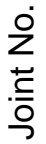 & $\begin{array}{l}\delta_{\max } \\
(\mathrm{mm})\end{array}$ & $\begin{array}{c}F_{\max } / \\
\delta_{\max } \\
(\mathrm{N} / \mathrm{mm})\end{array}$ & $\begin{array}{c}\delta_{\mathrm{p}} \\
(\mathrm{mm})\end{array}$ & $\begin{array}{c}F_{\mathrm{p}} / \delta_{\mathrm{p}} \\
(\mathrm{N} / \mathrm{mm})\end{array}$ & $\frac{\stackrel{0}{2}}{\frac{D}{\sigma}}$ & 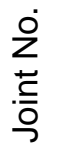 & $\begin{array}{c}\delta_{\max } \\
(\mathrm{mm})\end{array}$ & $\begin{array}{c}F_{\max } / \\
\delta_{\max } \\
(\mathrm{N} / \mathrm{mm})\end{array}$ & $\begin{array}{c}\delta_{\mathrm{p}} \\
(\mathrm{mm})\end{array}$ & $\begin{array}{c}F_{\mathrm{p}} / \delta_{\mathrm{p}} \\
(\mathrm{N} / \mathrm{mm})\end{array}$ \\
\hline \multirow{4}{*}{ 容 } & 1 & 23.17 & 73.77 & 11.36 & 92.40 & \multirow{4}{*}{$\sum_{0}^{0}$} & 1 & 21.63 & 75.75 & 12.34 & 87.02 \\
\hline & 2 & 18.59 & 79.90 & 9.10 & 100.38 & & 2 & 23.82 & 77.35 & 13.10 & 90.77 \\
\hline & 3 & 18.98 & 96.43 & 10.48 & 110.92 & & 3 & 23.26 & 106.59 & 11.46 & 126.88 \\
\hline & 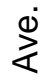 & 20.24 & 83.37 & 10.31 & 101.23 & & 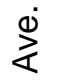 & 22.91 & 86.56 & 12.30 & 101.56 \\
\hline \multirow{4}{*}{ 导 } & 1 & 23.65 & 80.44 & 13.27 & 96.93 & \multirow{4}{*}{$\underbrace{0}_{0}$} & 1 & 24.32 & 86.28 & 12.66 & 103.91 \\
\hline & 2 & 23.30 & 75.82 & 11.63 & 94.58 & & 2 & 23.51 & 86.03 & 10.20 & 125.48 \\
\hline & 3 & 21.43 & 87.72 & 12.28 & 94.13 & & 3 & 24.30 & 68.34 & 18.75 & 65.90 \\
\hline & 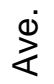 & 22.79 & 81.33 & 12.39 & 95.22 & & 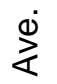 & 24.04 & 80.22 & 13.87 & 98.43 \\
\hline \multirow{4}{*}{$\stackrel{\vec{\alpha}}{\Delta}$} & 1 & 20.00 & 81.04 & 11.07 & 99.83 & \multirow{4}{*}{$\vec{a}$} & 1 & 22.17 & 102.34 & 13.19 & 125.04 \\
\hline & 2 & 14.17 & 80.65 & 7.28 & 95.17 & & 2 & 23.48 & 76.95 & 12.38 & 99.36 \\
\hline & 3 & 16.77 & 93.79 & 8.81 & 110.46 & & 3 & 22.57 & 97.60 & 10.00 & 130.85 \\
\hline & 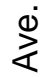 & 16.98 & 85.16 & 9.05 & 101.82 & & 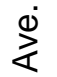 & 22.74 & 92.29 & 11.86 & 118.42 \\
\hline
\end{tabular}

The total reaction moments of the joints obtained from analytical calculation were used in a simplified numerical analysis of stress and strain of the loaded joints. The physical model was defined based on the experimental loading diagram of the joints, as shown in Fig. 2. Loading reaction forces $\left(F_{\mathrm{R}}\right)$ of each model of joints were calculated by the equation $F_{\mathrm{R}}=M_{\mathrm{R}} / d$ where $M_{\mathrm{R}}$ is analytical total reaction moment and $d$ is the moment arm. The values of loading forces used in numerical calculations are presented in Table 8. 
Table 8. Analytical Reaction Moments (Forces) and Numerical Displacement Results for Standard and Double Tenon Joints

\begin{tabular}{|c|c|c|c|c|}
\hline \multirow{2}{*}{} & \multicolumn{2}{|c|}{ Standard mortise and tenon joint } & \multicolumn{2}{c|}{ Double mortise and tenon joint } \\
\cline { 2 - 5 } & \multicolumn{2}{|c|}{ Tenon length } & \multicolumn{2}{c|}{ Tenon length } \\
\cline { 2 - 5 } & $20 \mathrm{~mm}$ & $30 \mathrm{~mm}$ & $20 \mathrm{~mm}$ & $30 \mathrm{~mm}$ \\
\hline$M_{\mathrm{R}}(\mathrm{Nm})$ & 120.46 & 186.73 & 208.07 & 350.32 \\
\hline$F_{\mathrm{R}}(\mathrm{N})$ & 587.44 & 910.61 & 1014.68 & 1708.38 \\
\hline$\delta_{l}(\mathrm{~mm})$ & 2.14 & 3.26 & 2.32 & 3.81 \\
\hline
\end{tabular}

The numerical results of displacements of the defined point in the direction of the force $F_{\mathrm{R}}$ for standard and double tenon joints are shown in Table 8. Displacement results of loaded standard and double mortise and tenon joints are shown in Fig. 7. The maximum values of this translation displacement component occurred at the loaded end of the joint.

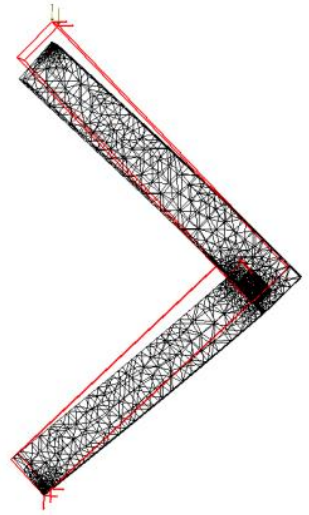

a)

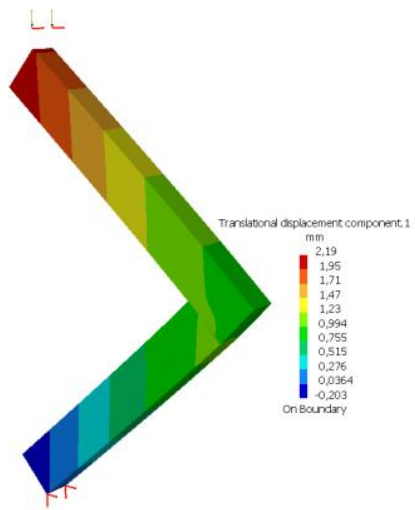

b)

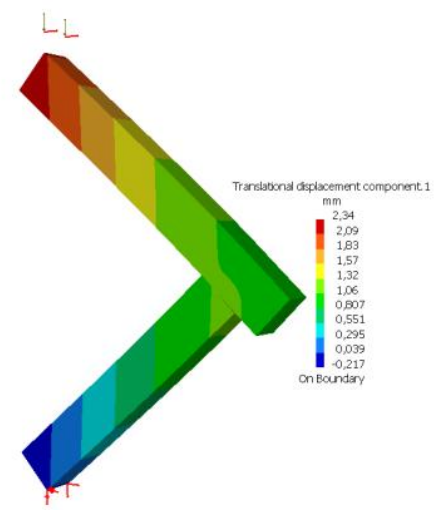

c)

Fig. 7. Numerical result of strain analysis (tenon length $20 \mathrm{~mm}$ ): a) deformation of the standard joint, b) and c) distribution of translational displacement component in the force direction of the standard mortise and tenon joint and double mortise and tenon joint, respectively

a)
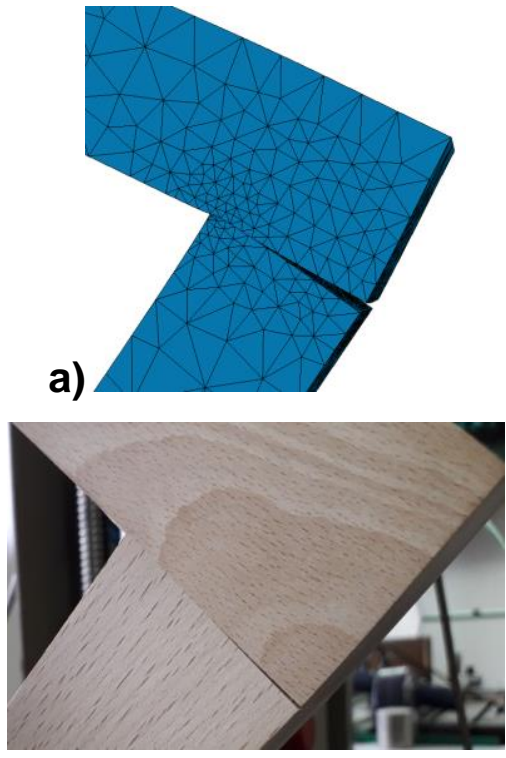

b)
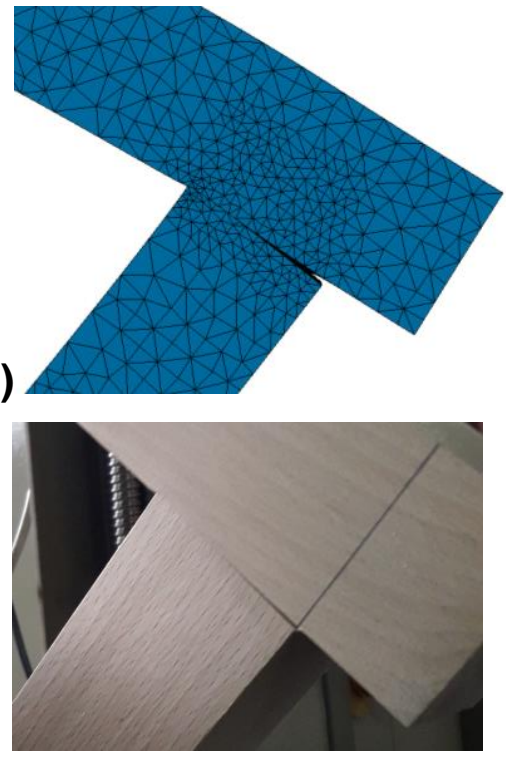

Fig. 8. Deformations obtained by numerical calculation and the test (tenon length $20 \mathrm{~mm}$ ): a) standard mortise and tenon joint, b) double mortise and tenon joint 
The joint deformations were obtained by numerical calculation and the test shows that a gap occurred among the tenon shoulder and the mortise wall in the tension zone of the joint, Fig. 8. The gap appeared due to the deformation of the mortise wall in the pressure zone of the joint i.e. due to the different values of the modulus of elasticity perpendicular to the fibers and parallel to the fibers.

The load-displacement graph of the standard mortise and tenon joint and double mortise and tenon joint for both tenon lengths obtained by numerical and experimental methods is shown in Fig. 9. Experimental data were obtained by analyzing only the linear elastic zone i.e. the initial nonlinear zone was excluded. Based on the numerical results, the percentages of the ratio of displacement for tenon lengths $20 \mathrm{~mm}$ and tenon length 30 $\mathrm{mm}$ was $66 \%$ the standard tenon joints and $61 \%$ for the double tenon joints which were approximately the same as the ratio of total reaction moment for tenon lengths of $20 \mathrm{~mm}$ and tenon lengths of $30 \mathrm{~mm}$. As can be seen in Fig 9, increasing the tenon length from 20 $\mathrm{mm}$ to $30 \mathrm{~mm}$ for both of type joints did not increase the stiffness. This means that the joint with a tenon length $30 \mathrm{~mm}$ kept the achieved rigidity to a higher load. Also, the experimental results did not show a quite defined and remarkable effect of the tenon length on stiffness at the proportional limit of the standard and double mortise and tenon joints. The numerical results showed much smaller displacements of the point, i.e., much higher stiffness of the joints than the displacements measured in the testing. A comparison of the numerical and experimental results indicates that the accuracy of the established models with the introduced simplifications and assumptions is not large but it was still capable to predict behavior of loaded joints in the domain of linear-elastic deformation.

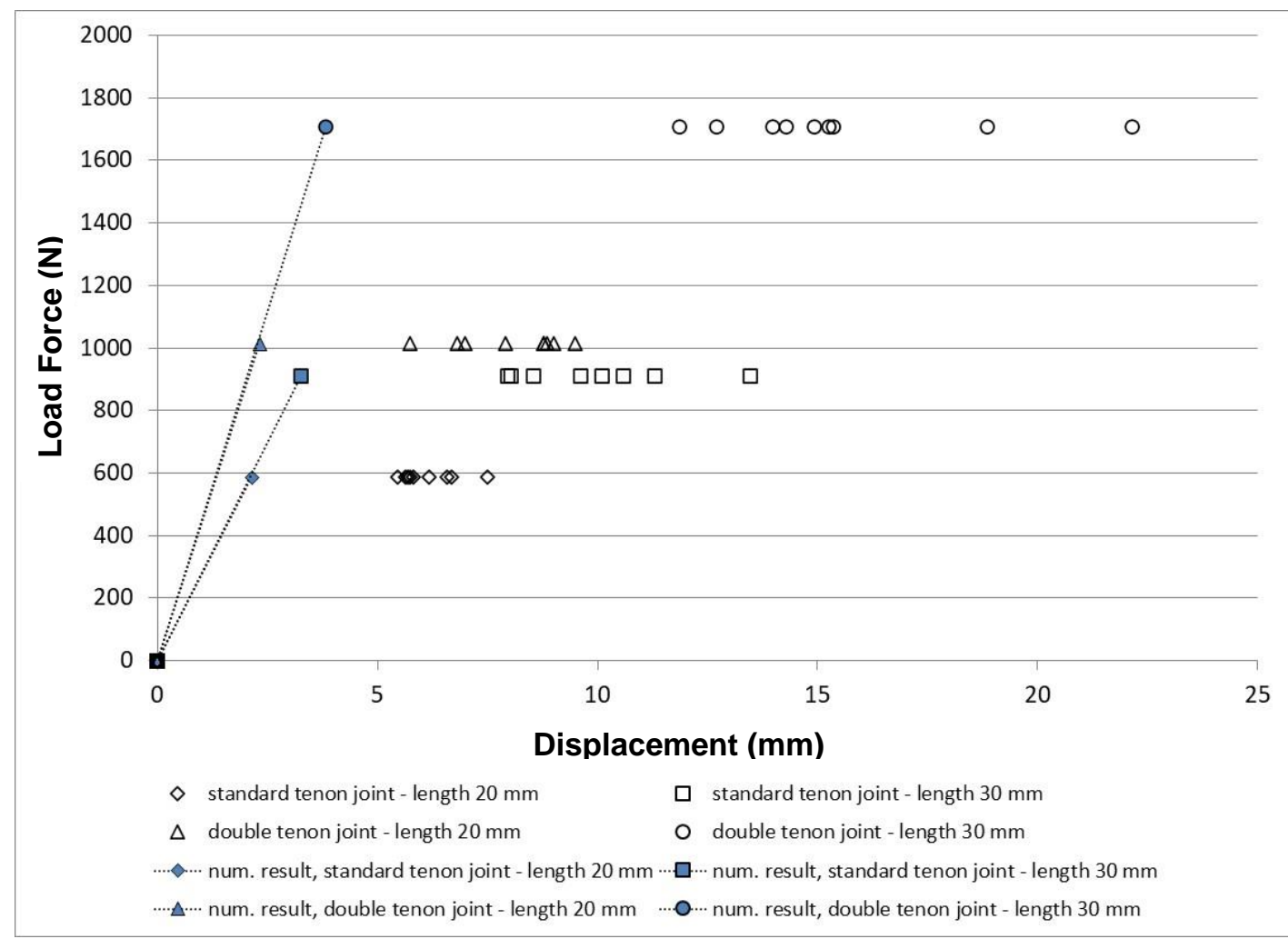

Fig. 9. Load-displacement graph of standard mortise and tenon joint and double mortise and tenon joint obtained by numerical calculation and the test (linear elastic zone only) 
The distribution of effective stress (the Von Mises stress) in the standard and double mortise and tenon joints for both tenon length are shown in Figs. 10 and 11.

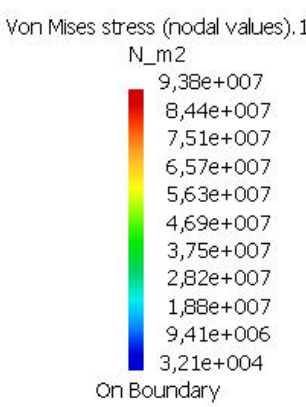

a)

Von Mises stress (nodal values). 1

$$
\text { N_m2 }
$$

$7,48 e+007$

$6,74 e+007$

$5,99 e+007$

$5,24 e+007$

$4,49 e+007$

$3,74 e+007$

$2,99 e+007$

$2,25 e+007$

$1,5 \mathrm{e}+007$

$7,49 e+006$

$5,06 e+003$

on Boundary
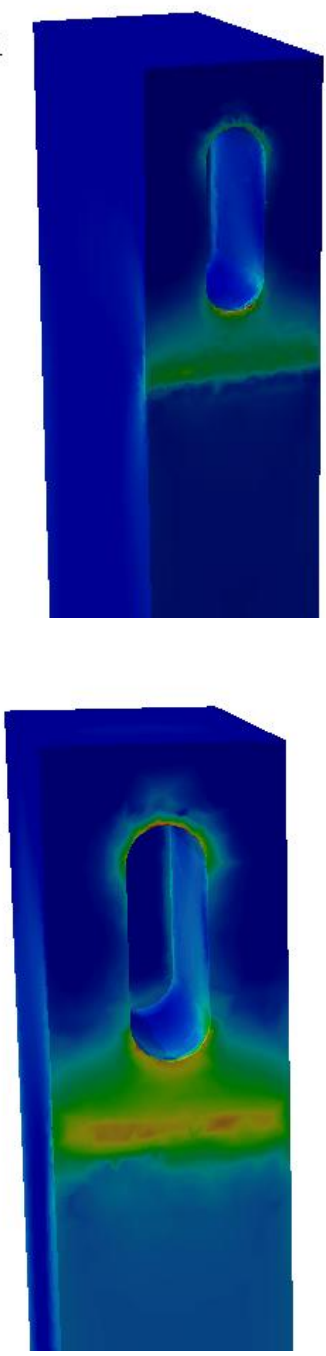
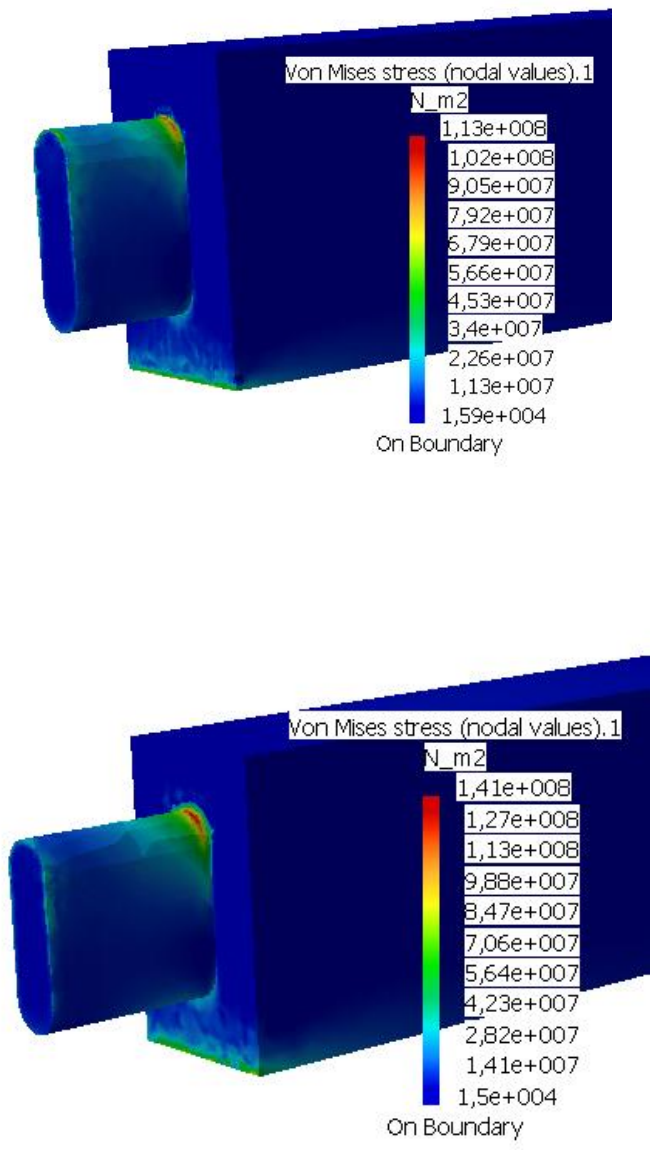

b)

Fig. 10. Distribution of von Mises stress of standard mortise and tenon joints: a) tenon length $20 \mathrm{~mm}, \mathrm{~b}$ ) tenon length $30 \mathrm{~mm}$

The Von Mises stress is commonly used approximation that assumes that the material is isotropic and it can be a sufficiently good indicator of the stress state of a loaded construction made of orthotropic material. The maximum and increased values of von Mises stress occurred in the lower edge zone of mortise piece and in the zone of tenon upper edge cheek and in the lower zone of tenon shoulder. These zones are, along with the tenon cheeks, the places where the highest deformations and eventually fractures occurred. All other joint surfaces sustained smaller stress. 


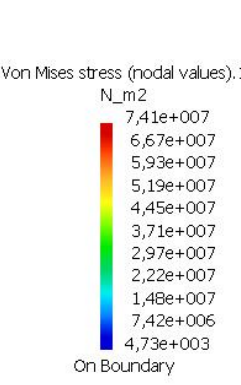

a)
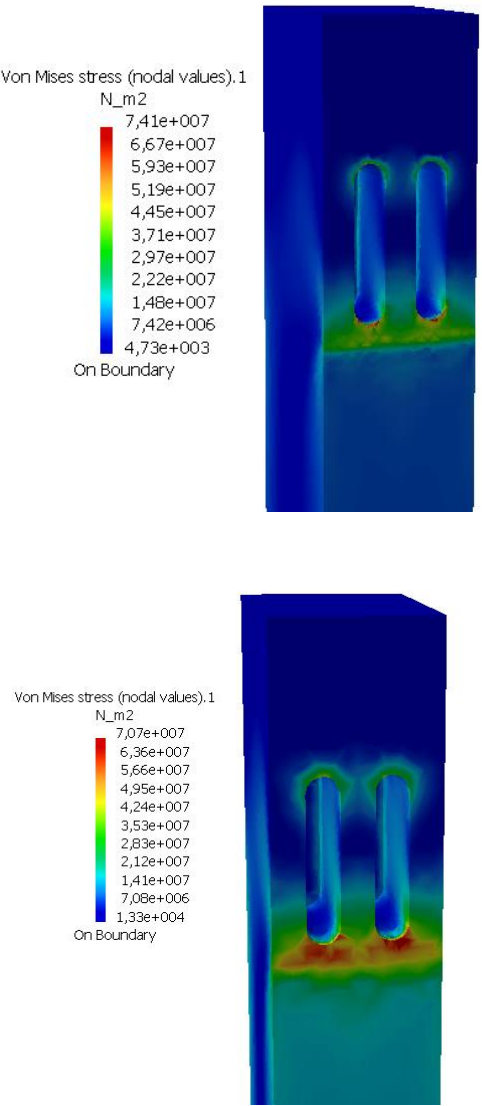
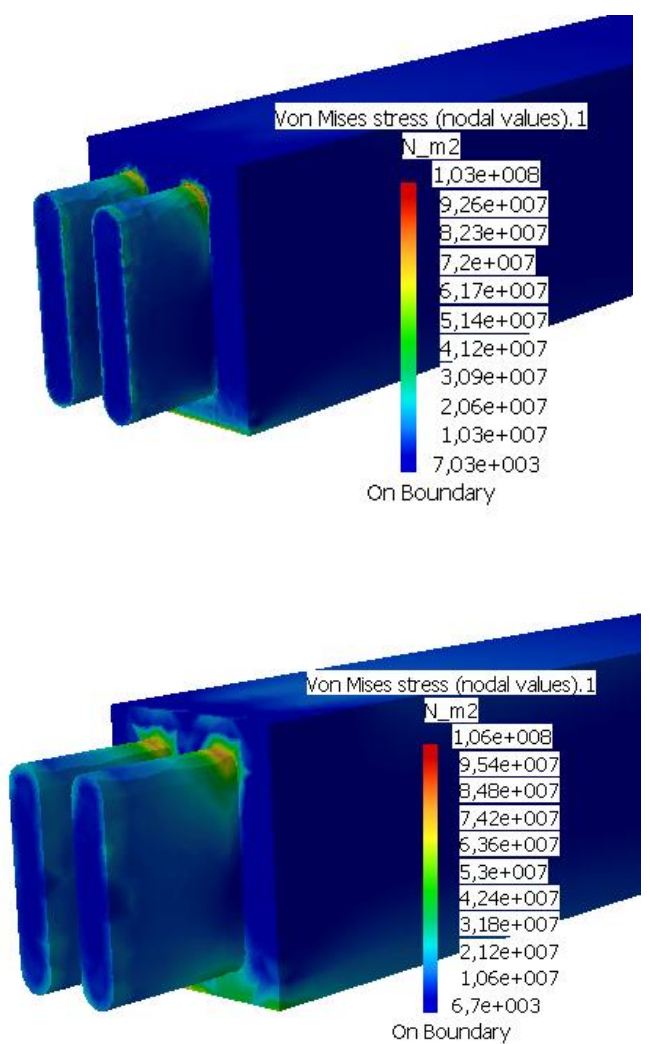

b)

Fig. 11. Distribution of von Mises stress of double mortise and tenon joints: a) tenon length 20 $\mathrm{mm}, \mathrm{b}$ ) tenon length $30 \mathrm{~mm}$

\section{CONCLUSIONS}

1. The tenon length has an effect on the maximal moment (moment capacity) and the proportional moment of the standard mortise and tenon joint and double mortise and tenon joint. The value of the maximal moment and the proportional moment increased as tenon length increased for both joint types and all three used glues (PVAc1, PVAc2, and PU). The joints constructed by using PU glue had a higher percentage increase than those with PVAc glue.

2. The percentage of the ratio of an average value of proportional and maximal moment of the standard tenon joints with tenon length $20 \mathrm{~mm}$ was above $70 \%$ for all glue type. These percentages were lower for all other set of joints, and those percentages were approximately $64 \%$.

3. The differences among the average experimental value of joint stiffness with two different tenon lengths $(20 \mathrm{~mm}$ and $30 \mathrm{~mm}$ ) for both analyzed joint types and all three used glues (PVAc1, PVAc2, and PU) were not clearly observed.

4. Joint stiffness was higher for the load below the proportional limit for both joint types, both tenon lengths and glues. The double mortise and tenon joints glued with PU and with tenon length $30 \mathrm{~mm}$ had the highest average values of joints stiffness. 
5. Analytical calculated reaction moments increased more than experimental moment values as tenon length increased for both standard and double tenon joints. The ratio of the reaction moment for tenon length $20 \mathrm{~mm}$ and for tenon length $30 \mathrm{~mm}$ was approximately under two thirds for both standard and double tenon joints. The analytical reaction moments had lower values than maximal moment (moment capacities) for all types of joints and tenon lengths. In fact, the reaction moment had generally lower values than the proportional moments for the standard mortise and tenon joints as opposed to the double mortise and tenon joints.

6. The numerical results of displacement showed much higher stiffness of the joints than the stiffness obtained by the test. Von Mises stress distribution of the loaded joints showed the characteristic zones of the maximum and increased stress values likewise those monitored in the analytical calculations.

7. Numerical and analytical results show that the presented procedures could be successfully used to achieve approximate data of mechanical properties of wood structures and joints and that are capable to estimate behavior of loaded profile adhesive joints in the linear elastic range.

\section{REFERENCES CITED}

Bardak, T., Tankut, A. N., Tankut, N., Aydemir, D., and Sozen, E. (2017). "The bending and tension strength of furniture joints bonded with polyvinyl acetate nanocomposites," Maderas. Ciencia y Tecnología 19(1), 51-62. DOI: 10.4067/S0718221X2017005000005

Derikvand, M., Ebrahimi, G., and Eckelman, C. A. (2014). "Bending moment capacity of mortise and loose-tenon joints," Wood and Fiber Science 46(2), 1-8.

Derikvand, M., and Pangh, H. (2016). "A modified method for shear strength measurement of adhesive bonds in solid wood," BioResources 11(1), 354-364. DOI: 10.15376/biores.11.1.354-364

Elek, L., Kovács, Z., Csóka, L., and Agarwal, C. (2020). "Evaluation of the effect of optimal fit criteria on the compressive strength of open mortise and tenon corner joints," European Journal of Wood and Wood Products 78, 351-363. DOI: 10.1007/s00107-020-01509-w

Hajdarević, S., and Busuladžić, I. (2015). "Stiffness analysis of wood chair frame," Procedia Engineering 100, 746-755. DOI: 10.1016/j.proeng.2015.01.428.

Hajdarević, S., and Martinović, S. (2014). "Effect of tenon length on flexibility of mortise and tenon joint," Procedia Engineering 69, 678-685. DOI: 10.1016/j.proeng.2014.03.042.

Horman, I., Hajdarević, S., Martinović, S., and Vukas, N. (2010). "Numerical analysis of stress and strain in a wooden chair," Drvna Industrija 61(3), 151-158.

Hrovatin, J., Zupančič, A., Šernek, M., and Oblak, L. (2013). "The fracture moment of corner joint bonded by different glues," Drvna Industrija 64 (4), 335-340. DOI: 10.5552/drind.2013.1248

Hu, W., and Guan, H. (2017). "Research on withdrawal strength of mortise and tenon joint by numerical and analytic methods," Wood Research 62(4), 575-586.

Hu, W., Wan, H., and Guan, H. (2019a). "A finite element model of semi-rigid mortiseand-tenon joint considering glue line and friction coefficient," Journal of Wood 
Science 65, Article number 14. DOI: 10.1186/s10086-019-1794-4

Hu, W., Wan, H., and Guan, H. (2019b). "Size effect on the elastic mechanical properties of beech and its application in finite element analysis of wood structures," Forests 10, 783. DOI: $10.3390 / \mathrm{f} 10090783$

ISO 13061-1 (2014). "Physical and mechanical properties of wood-Test methods for small clear wood specimens - Part 1: Determination of moisture content for physical and mechanical test," International Organization for Standardization, Geneva, Switzerland.

Kasal, A., Eckelman, C. A., Haviarova, E., Erdil, Y. Z., and Yalcin I. (2015). "Bending moment capacities of L-shaped mortise and tenon joints under compression and tension loadings," BioResources 10(4), 7009-7020. DOI: 10.15376/biores.10.4.70097020.

Kasal, A., Smardzewski, J., Kuşkun, T., and Erdil, Y. Z. (2016). "Numerical analyses of various sizes of mortise and tenon furniture joints," BioResources 11(3), 6836-6853. DOI: 10.15376/biores.11.3.6836-6853

Likos, E., Haviarova, E., Eckelman, C. A., Erdil, Y. Z., and Ozcifci, A. (2012). "Effect of tenon geometry, grain orientation, and shoulder on bending moment capacity and moment rotation characteristics of mortise and tenon joints," Wood and Fiber Science 44(4), 462-469.

Máchová, E., Langová, N., Réh, R., Joščák, P., Krišták, L., Holouš, Z., Igaz, R., and Hitka, M. (2019). "Effect of moisture content on the load carrying capacity and stiffness of corner wood-based and plastic joints, " BioResources 14(4), 8640-8655. DOI: $10.15376 /$ biores. 14.4.8640-8655

Podlena, M., and Borůvka, V. (2016). "Stiffness coefficients of mortise and tenon joints used on wooden window profiles," BioResources 11(2), 4677-4687. DOI: 10.15376/biores.11.2.4677-4687.

Podlena, M., Böhm, M., Múčka, M., and Bomba, J. (2017). "Determination of the bending moment of a dowel and tenon joint on window profile IV 92 of a wooden window," BioResources 12(2), 4202-4213. DOI: 10.15376/biores.12.2.4202-4213.

Skarvelis, M., and Mantanis, G. I. (2013). "Physical and mechanical properties of beech wood harvested in the Greek public forests," Wood Research 58(1), 123-130.

Smardzewski, J. (2008). "Effect of wood species and glue type on contact stresses in a mortise and tenon joint," Journal of Mechanical Engineering Science 222(12), 22932299. DOI: 10.1243/09544062JMES1084.

Vassiliou, V., Barboutis, I., and Kamperidou, V. (2016). "Strength of corner and middle joints of upholstered furniture frames constructed with black locust and beech wood," Wood Research 61(3), 495-504.

Wilczyński, A., and Warmbier, K. (2003). "Effect of joint dimensions on strength and stiffness of tenon joints," Folia Forestalia Plonica, Seria B, Zeszyt 34, 53-66.

Záborský, V., Borůvka, V., Kašičková, V., and Ruman, D. (2017). "Effect of wood species, adhesive type, and annual ring directions on the stiffness of rail to leg mortise and tenon furniture joints," BioResources 12(4), 7016-7031. DOI:

10.15376/biores.12.4.7016-7031

Article submitted: May 1, 2020; Peer-review completed: June 29, 2020; Revised version received and accepted: July 24, 2020; Published: September 14, 2020.

DOI: $10.15376 /$ biores.15.4.8249-8267 